\title{
Unilineage Dysplasia Present
}

National Cancer Institute

\section{Source}

National Cancer Institute. Unilineage Dysplasia Present. NCI Thesaurus. Code C82592.

A hematologic test result indicating dysplastic changes in only one of the myeloid cell lineages in the bone marrow. 